\title{
Improved detection of Mycobacterium tuberculosis using two independent PCR targets in a tertiary care centre in South India
}

\author{
Ramya Barani, Gopalsamy Sarangan, Tessa Antony, Soundararajan Periyasamy, Anupma Jyoti \\ Kindo, Padma Srikanth
}

Department of Microbiology, Sri Ramachandra University, Porur, Chennai, India

\begin{abstract}
Introduction: Tuberculosis (TB) causes significant morbidity and mortality worldwide as one of the leading infectious diseases. In India, more than 1.8 million new cases occur every year. Rapid and accurate diagnosis of TB would improve patient care and limit its transmission. This study aimed to evaluate a dual target polymerase chain reaction (PCR) diagnostic assay to detect Mycobacterium tuberculosis from pulmonary and extra-pulmonary samples at a tertiary care centre in South India.

Methodology: Samples were collected from patients with a low index of suspicion of TB. Acid-fast smears were performed by Auramine O fluorescent microscopy and PCR was performed by using two site-specific primer pairs targeting IS6110 by nested PCR and $T R C_{4}$ by conventional PCR. Amplified products for IS6110 and/or TRC 4 were indicative of M. tuberculosis.

Results: Among 114 (19 pulmonary and 95 extra-pulmonary) samples tested by PCR assay, 12 (11\%) were positive for both IS6110 and $T R C_{4}$, of which $11(10 \%)$ were non-respiratory and one was (1\%) respiratory in origin. PCR for $T R C_{4}$ alone was positive for eight (7\%) nonrespiratory and two (2\%) respiratory samples, while IS6110 alone tested positive for six (5\%) non-respiratory samples and one (1\%) respiratory sample. Of a total of 29 PCR positive samples, 17 (15\%) were acid-fast smear positive.

Conclusion: Although the target site of IS6110 is specific for M. tuberculosis, some strains from South India may lack this region. Therefore, the use of an additional target site $\left(T R C_{4}\right)$ is required for improved detection of M. tuberculosis.
\end{abstract}

Key words: Mycobacterium tuberculosis; polymerase chain reaction; IS6110; $\mathrm{TRC}_{4}$; South India

J Infect Dev Ctries 2012; 6(1):46-52.

(Received 16 June 2010 - Accepted 27 July 2011)

Copyright (C) 2012 Barani et al. This is an open-access article distributed under the Creative Commons Attribution License, which permits unrestricted use, distribution, and reproduction in any medium, provided the original work is properly cited.

\section{Introduction}

Tuberculosis (TB) is the major cause of death by a bacterial infectious disease worldwide. The World Health Organization (WHO) estimates that there were approximately 8.9 to 9.9 million incident cases of TB and about 1.1 to 1.7 million TB deaths globally in 2008. India contributes the highest number of new cases, accounting for $20 \%$ of the global burden, of which approximately $1.2 \%$ occur in persons with HIV [1]. In India, pulmonary TB is the most common form of the disease; however, extra-pulmonary TB comprises $20 \%$ of cases [2]. Early diagnosis and identification of $\mathrm{TB}$ are essential in instituting effective, timely therapy. Diagnosis of TB is mainly based on clinical presentation, histopathology, and the demonstration of acid-fast bacilli (AFB) in smears and the isolation of Mycobacterium tuberculosis from culture. These diagnostic criteria have limitations that include atypical clinical presentations of disease, and poor sensitivity and specificity of AFB microscopy, particularly with paucibacillary specimens. Culture for $M$. tuberculosis usually takes four to six weeks to grow on solid media, delaying time to results. The diagnosis of extra-pulmonary $\mathrm{TB}$ is particularly difficult to establish, especially in developing countries because of the paucibacillary nature of extra-pulmonary specimens and because the signs and symptoms of disease can be non-specific $[3,4]$.

Polymerase Chain Reaction (PCR) allows detection of $M$. tuberculosis directly from clinical specimens [5] and, given the limitations of conventional culture methods, PCR is currently the most sensitive, rapid diagnostic laboratory method [6]. However, considering the number of cases diagnosed with TB in India, there is an urgent need to use multiple diagnostic modalities for rapid detection of M. tuberculosis to control the transmission of TB. In the United States, molecular tests are routinely performed to detect $M$. tuberculosis. In India, 
however, molecular methods such as PCR are underutilized, even when there are no cost constraints.

Some of the targets used to amplify $M$. tuberculosis for detection include $I S 6110,65 \mathrm{kDa}$, and $38 \mathrm{kDa}$ antigen coding regions [7]. Most studies have generally targeted the multi-copy IS6110 sequence of the genome $[7,8,9,10,11]$. However, the absence or the presence of only a few copies of this sequence has been reported in some strains, particularly those from Southeast Asia [12]: A large number of clinical isolates of M. tuberculosis from South India [13] had either a single copy $(40 \%)$ or no copy (4\%) of IS6110, thus indicating the need to incorporate additional target sites for improved detection. $T R C_{4}$, which is specific for $M$. tuberculosis complex, was sequenced and patented by the Tuberculosis Research Centre (TRC-ICMR), Chennai, India, as an ideal target for PCR assays to identify $M$. tuberculosis; especially in strains carrying no copies of IS6110 in tuberculous meningitis and tubercular pleuritis patients $[13,14,15]$.

The present study was undertaken to detect $M$. tuberculosis by a PCR assay that combined targets IS6110 and $T R C_{4}$ as well as by acid-fast fluorescent microscopy from pulmonary and extra-pulmonary specimens obtained from patients with undiagnosed fever who attended specialty clinics at a tertiary care center in South India. Tuberculosis may be underdiagnosed in these patients as the primary problems are specialty related.

\section{Methodology}

\section{Patient population}

This study was conducted from January 2007 to August 2008, utilizing patients seen in specialty care clinics for nephrology, neurology, general medicine, obstetrics and gynaecology, gastro-enterology and cardiology of a tertiary referral centre. The clinical samples collected from the clinic patients who had undiagnosed fever and co-morbidities were tested for detection of M. tuberculosis using a PCR assay.

\section{Specimens analyzed}

Among the 114 specimens analyzed, 95 (83\%) were extra-pulmonary, consisting of 40 urine samples, 18 cerebrospinal fluids (CSF), 14 body fluids, seven pus, five tissues, five continuous ambulatory peritoneal dialysis fluid (CAPD), two endometrial aspirates, and one specimen from each of the following: gastric aspirate, bone marrow aspirate, fine needle aspirate, and semen. The 19 (17\%) pulmonary specimens tested consisted of 13 pleural fluids, four sputum samples, and one from each of the following: endo-tracheal secretion (ET), and bronchoalveolar lavage (BAL).

\section{Sample processing}

All specimens were sent to the laboratory in sterile containers and were processed per the manufacturer's instructions (commercially available kit; GeNei, Bangalore, India). In brief, the specimens were processed and decontaminated by $\mathrm{N}$-acetyl LCysteine (NALC)-NaOH method and then centrifuged at $8,000 \mathrm{rpm}$ for 15 minutes. All collected sediments were aliquoted into multiple vials and the remaining were processed for PCR within 24 hour or stored at $-20^{\circ} \mathrm{C}$ in a freezer until tested. Fluorescent smear microscopy by auramine-O method was performed from each specimen using standardized procedures [16]. Tissue biopsy specimens were homogenized in a sterile container (GeNei, Bangalore) before testing. With a view to rapid diagnosis, the clinicians sent the samples only for PCR; therefore, culture for M. tuberculosis was not performed.

\section{Quality control}

Reagents were aliquoted and each aliquot was used only once. Sterile microfuge tubes and PCR tubes were used for the PCR assay. Reagent preparation, DNA extraction, DNA amplification and detection were performed in separate rooms to avoid cross-contamination of amplicons. A positive control was included in each test and distilled water was included as a negative test control. Uracil-Nglycosylase (UNG) was used in the amplification process to avoid post PCR DNA contamination.

\section{Amplification of mycobacterial DNA}

DNA was extracted from specimens per the manufacturer's instructions (GeNei, Bangalore, India).

(a) Nested polymerase chain reaction (nPCR): A single tube nested PCR was performed using the proprietary IS6110 primer sequences (GeNei, Bangalore, India) targeting $M$. tuberculosis. The DNA was amplified with forward and reverse primers of the outer region of $M$. tuberculosis and the first product was amplified with the inner primer in the second amplification per the manufacturer's instructions (GeNei, Bangalore, India).

The PCR conditions for outer sense primers for the first round of amplification were as follows: initial denaturation at $22^{\circ} \mathrm{C}$ for 10 minutes, $94^{\circ} \mathrm{C}$ for 5 
Table 1. Comparison of PCR targeting IS6110 and $T R C_{4}$ in clinical samples from various specialty clinics wth smear microscopy

\begin{tabular}{|c|c|c|c|c|c|c|c|c|}
\hline \multirow{2}{*}{$\begin{array}{l}\text { Origin of } \\
\text { sample }\end{array}$} & \multirow[t]{2}{*}{ Speciality clinics } & \multirow{2}{*}{$\begin{array}{l}\text { Clinical } \\
\text { Sample }\end{array}$} & \multicolumn{2}{|c|}{ AFB Smear } & \multirow{2}{*}{$\begin{array}{c}\text { Number } \\
\text { of PCR } \\
\text { positives }\end{array}$} & \multicolumn{3}{|c|}{ PCR Positive } \\
\hline & & & Positive & Negative & & $\begin{array}{c}\text { IS6110 } \\
\text { alone }\end{array}$ & $\begin{array}{l}\mathrm{TRC}_{4} \\
\text { alone }\end{array}$ & $\begin{array}{c}\mathrm{IS6110}+ \\
\mathrm{TRC}_{4}\end{array}$ \\
\hline \multirow{10}{*}{$\begin{array}{c}\text { Extra- } \\
\text { pulmonary }\end{array}$} & Nephrology & Urine & 5 & 6 & 11 & 4 & 3 & 4 \\
\hline & \multirow{4}{*}{$\begin{array}{l}\text { Obstetrics } \\
\text { Gynaecology }\end{array}$} & $\begin{array}{l}\text { Peritoneal } \\
\text { fulid }\end{array}$ & - & 1 & 1 & 1 & - & - \\
\hline & & $\begin{array}{l}\text { peritoneal } \\
\text { nodule }\end{array}$ & 1 & - & 1 & - & - & 1 \\
\hline & & Urine & 1 & - & 1 & 1 & - & - \\
\hline & & $\begin{array}{l}\text { Endometrial } \\
\text { aspirate }\end{array}$ & 1 & 1 & 2 & - & 2 & - \\
\hline & Neurology & Pus & 4 & - & 4 & - & 2 & 2 \\
\hline & \multirow[t]{2}{*}{ Gastro enterology } & Pus & 1 & 1 & 2 & - & - & 2 \\
\hline & & Urine & - & 1 & 1 & - & 1 & - \\
\hline & Cardiology & Colonoscopy & 1 & - & 1 & - & - & 1 \\
\hline & General medicine & Urine & 1 & - & 1 & - & - & 1 \\
\hline \multirow{4}{*}{ Pulmonary } & Nephrology & Sputum & - & 1 & 1 & - & 1 & - \\
\hline & Neurology & $\begin{array}{l}\text { Endotracheal } \\
\text { secretion }\end{array}$ & - & 1 & 1 & - & 1 & - \\
\hline & Cardiology & Sputum & 1 & - & 1 & - & - & 1 \\
\hline & General medicine & pleural fluid & 1 & - & 1 & 1 & - & - \\
\hline \multicolumn{3}{|c|}{ Totals } & 17 & 12 & 29 & 7 & 10 & 12 \\
\hline
\end{tabular}

minutes, 20 cycles of $94^{\circ} \mathrm{C}$ for 30 seconds, $68^{\circ} \mathrm{C}$ for one minute, $72^{\circ} \mathrm{C}$ for one minute, and a final extension of $72^{\circ} \mathrm{C}$ for 7 minutes. The PCR conditions using the inner set of primers for the second amplification consisted of initial denaturation step at $94^{\circ} \mathrm{C}$ for 5 minutes, 30 cycles of $94^{\circ} \mathrm{C}$ for 30 seconds, $68^{\circ} \mathrm{C}$ for 30 seconds, $72^{\circ} \mathrm{C}$ for 30 seconds and a final extension of $72^{\circ} \mathrm{C}$ for 7 minutes.

(b) Conventional PCR targeting $T R C_{4}$ : The primer and red dye Master Mix kit were obtained from Bangalore Genei. Samples were amplified using $\mathrm{TRC}_{4}$ Primer-1

$\left(5^{\prime}-\right.$ GACAACGACGTGCGCCTACT-3') and $T R C_{4}$ primer-2 ACCGAATTAGCGTAGCTCC-3'). The amplification cycles were performed on an automated thermal cycler (MJ Research Corp, Encino, CA, USA). The initial step of denaturation was not performed. The amplification consisted of 35 cycles of $94^{\circ} \mathrm{C}$ for one minute, $58^{\circ} \mathrm{C}$ for one minute, $72^{\circ} \mathrm{C}$ for one minute and the final primer extension step at $72^{\circ} \mathrm{C}$ for 10 minutes.

The detection of amplified PCR products was determined using agarose gel $(2 \%)$ electrophoresis stained with ethidium bromide $(0.5 \mu \mathrm{g} / \mathrm{ml})$ and subsequently visualized on the $260 \mathrm{~nm}$ wavelength UV transilluminator of the gel documentation system (BIO-RAD, Hercules, CA,USA). A result was considered positive for the target when a well-defined DNA band corresponding to the sample was observed along with the controls and molecular weight marker. Samples which had amplified products measuring $123 \mathrm{bp}$ for IS6110 and $173 \mathrm{bp}$ for $T R C_{4}$ were considered positive (Figures 1 and 2).

The PCR tests were performed by investigator (RB) from pulmonary and extra-pulmonary samples. These samples were retested by another investigator (GS) who was blinded to the initial test results. The same techniques were used as outlined previously and the tests were performed in the same laboratory. 
Figure 1. PCR amplification of 123 bp region in IS6110 targeting PCR for M. tuberculosis

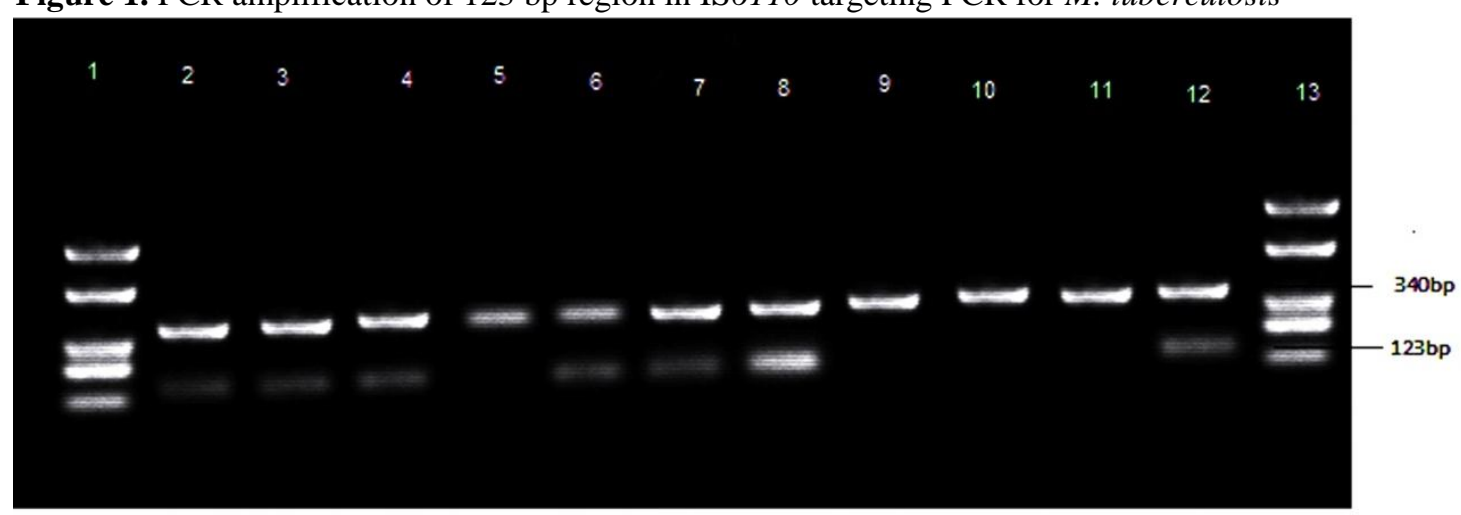

Lanes 1 and 13: molecular weight marker; Lanes 2, 3, 4: positive for 123 bp; Lanes 5 and 9: negative control; Lanes 6, 7, 8: positive for 123 bp; Lanes 10 and 11: negative for $123 \mathrm{bp}$; Lane 12: positive control

Figure 2. PCR amplification of 173 bp region in TRC4 gene of M. tuberculosis

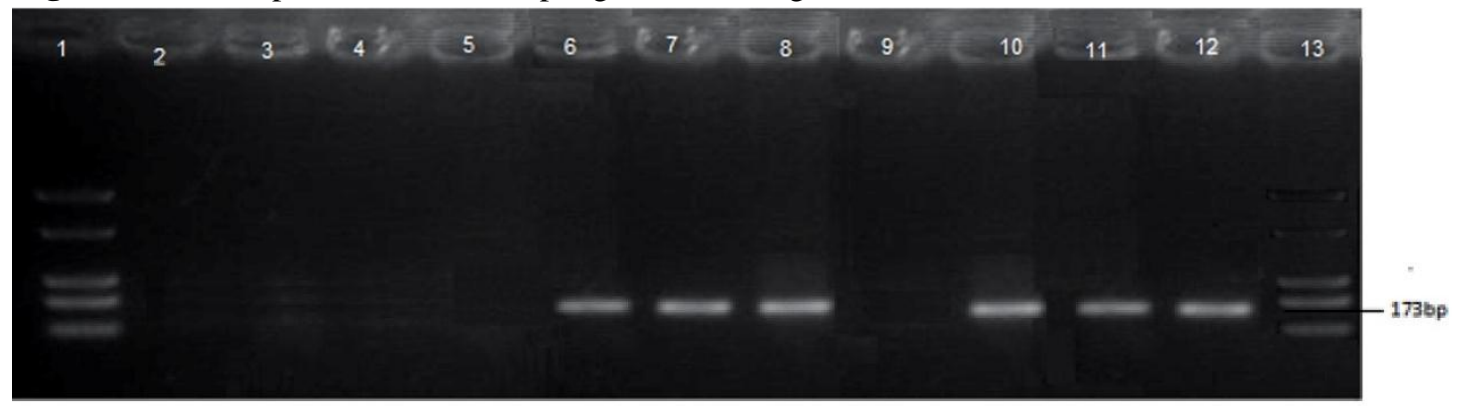

Lanes 1 and 13: molecular weight marker; Lanes 2, 3, 4: negative for 173 bp; Lanes 5 and 9: negative control; Lanes 6, 7, 8, 10, 11: positive for 173 bp; Lane 12: positive control

\section{Results}

Of the 114 specimens analyzed, $17(15 \% ; 15$ non-pulmonary and 2 pulmonary) were AFB smearpositive. These included seven urine samples, five pus samples, and one of the following: peritoneal nodule, colonoscopy fluid, endometrial aspirate, pleural fluid, and sputum. All 17 AFB smear-positive specimens were also PCR-positive for $M$. tuberculosis. With regard to PCR target detection, four samples were IS6110 positive, five were $T R C_{4}$ positive and eight were positive for both IS6110 and $T R C_{4}$. Table 1 shows the distribution of nonpulmonary and pulmonary specimens, their PCR reactions, and their AFB smear results.

In addition, there were 12 AFB smear-negative specimens that were also PCR positive. These included seven urine samples, one peritoneal fluid, one sputum, one endometrial aspirate, one pus sample, and one endotracheal secretion. Of these, three specimens were PCR-positive for IS6110 alone, five for $T R C_{4}$ alone, and four were positive for both IS6110 and $T R C_{4}$.
Overall, 25 non-pulmonary and four pulmonary specimens $(29 / 114,25 \%$ of all samples) were positive using the dual target PCR assay. Therefore, as compared to smear microscopy, the PCR method showed a $71 \%$ improvement in detection of $M$. tuberculosis.

Analysis of samples by PCR using IS6110 and $T R C_{4}$ showed seven samples (6.1\% of all specimens) to be positive for IS6110 but negative for $T R C_{4}$ (six non-respiratory and one pleural fluid), while 10 samples (9\%) were positive for $T R C_{4}$ but negative for IS6110 (four urine samples, two endometrial aspirates, two pus samples, one sputum and one endotracheal secretion). Twelve specimens were positive for both IS6110 and $T R C_{4}(11 \%)$. These included five urine samples, four pus samples, one peritoneal nodule, one colonoscopy fluid, and one sputum.

In summary, sample analysis by PCR using IS6110 and $\mathrm{TRC}_{4}$ resulted in seven samples positive for IS6110 and negative for TRC4 and 10 samples positive for $\mathrm{TRC}_{4}$ and negative for IS6110. Seventeen 
samples were positive by smear microscopy and were also PCR positive.

\section{Discussion}

TB remains a major global public health problem, especially in India. The clinical utility of detecting M. tuberculosis by PCR is its reduction in the time to detection and its accuracy in detecting the pathogen in AFB smear-negative paucibacillary specimens. A recent meta-analysis [17] concluded that fluorescence microscopy was approximately $10 \%$ more sensitive than conventional carbol fuchsin AFB stains and takes less time to read, but its limitations include the expense of purchasing a fluorescent microscope and the requirement for reading slides in a darkroom.

In our study, PCR was performed by amplification of the IS6110 insertion sequence, which belongs to the IS3 family and is found in almost all members of the $M$. tuberculosis complex. Most strains carry 10 to 15 copies, which are present in a wide variety of chromosomal sites [18]. Previous studies have documented increased positivity using the IS6110 target in extra-pulmonary samples [7]. Negi et al. analyzed various targets specific for $M$. tuberculosis and reported the highest PCR positivity rates for pulmonary $(90 \%)$ and extra-pulmonary (77\%) samples when using IS6110; their results further confirmed the poor sensitivity of smear microscopy for pulmonary $(49 \%)$ and extrapulmonary (24\%) samples. Tiwari et al. reported 62\% PCR positivity in 133 extra-pulmonary samples and $22 \%$ positives by smear microscopy $[7,19]$. A potential problem with using this target is that some strains from certain parts of the world lack the IS6110 insertion sequence [20]. Even though PCR has been used in various laboratories; the sensitivity of PCR can vary from $11 \%$ to $81 \%$ [21]. Of the 114 samples analysed, 10 samples were IS6110 negative and $T R C_{4}$ positive, and seven samples were IS6110 positive and $T R C_{4}$ negative. Therefore, PCR using one target alone cannot detect all strains of $M$. tuberculosis but the use of two targets can improve pathogen detection. Previous studies conducted at the Tuberculosis Research Centre have similarly suggested that the sensitivity of PCR can be increased by using two sets of targets (IS6110 and $T R C_{4}$ ) to detect tuberculous meningitis and tubercular pleuritis $[14,15]$. Our study confirms the utility of dual targets to detect $M$. tuberculosis from extra-pulmonary sites.

Patients presenting to the nephrology clinic had chronic kidney disease (CKD), or were on dialysis or were post-transplant. Preliminary reports suggest that patients with hemodialysis, or CKD are more prone to genitourinary TB $[22,23]$. In India, genitourinary TB comprises $20 \%$ of all extra-pulmonary cases [24]. Since patients attending specialty clinics are receiving therapy for their primary disease, the symptoms of TB may be inconsistent or atypical in presentation. Very often the clinicians need evidence to aid them in the decision-making process to start anti-tuberculous drugs. Though culture remains the gold standard for TB diagnosis, solid culture media would require four to six weeks for growth. This delay would negatively affect patient care. While time to positivity with liquid culture media could be reduced to approximately one to four weeks, the financial investment and the need to subculture to solid media for identification pre-empts the advantage.

The majority of the clinical samples for testing were obtained from nephrology patients with CKD, renal failure, ongoing dialysis or post transplant. Extra-pulmonary specimens were the majority (83\%) analysed in our study and these cases may be missed had the PCR assay not been performed. In addition, the exclusion of the $T R C_{4}$ primers in PCR assays would have resulted in samples being reported as falsely negative. A major limitation of our study is that the results of PCR could not be compared with those of culture to obtain the performance characteristics of the dual-targeted molecular assay.

We suggest that PCR and other culture methods for M. tuberculosis detection be used in conjunction with clinical parameters to obtain a diagnosis of TB. PCR is a powerful diagnostic tool to detect $M$. tuberculosis, in extra-pulmonary TB cases [25,26]. Other rapid tests such as serology have at present no defined role in TB diagnosis [27]. While culture remains the gold standard, clinicians prefer to use rapid tests to solve clinical dilemmas. It is therefore important to optimize techniques to improve PCR assays to detect $M$. tuberculosis. Currently, there is an urgent need for diagnostic laboratories that utilize PCR methods to incorporate two primers (IS6110 \& $\mathrm{TRC}_{4}$ ) to increase accuracy of $M$. tuberculosis detection. Additional, rapid assays that are inexpensive are needed in resource poor areas to assist in curtailing the transmission of TB.

\section{Conclusion}

The data presented here support the development of PCR assays with dual targets to improve $M$. tuberculosis detection in clinical specimens. Since 
some strains from South India may lack the IS6110 element, PCR assays using primers from a repetitive element such as $T R C_{4}$ will improve test sensitivity. There is an urgent need to increase awareness of the importance of incorporating $T R C_{4}$ in the molecular diagnostic assays used for detection of $M$. tuberculosis. Our study focused on paucibacillary specimens from specialty care clinic patients, who often present with atypical clinical symptoms and AFB smear-negative specimens. We have demonstrated increased PCR sensitivity using dual targets for M. tuberculosis detection.

\section{References}

1. WHO (2009) Global tuberculosis control: a short update to the 2009 report Available at http://www.who.int/tb/publications/global_report/2009/upda te/en/index.html. Accessed 07 May 2010.

2. Arora VK and Chopra VK (2007) Extra-pulmonary tuberculosis. Indian Journal of Tuberculosis. Indian $\mathbf{J}$ Tuberc 54:165-167.

3. Massoud Hajia, Mohammad Rahbar, Rana Amini (2009) Is PCR assay reliable for diagnosis of extra-pulmonary tuberculosis? Afr J Microbiol Res 3: 877-881.

4. Noussair N, Bert F, Leflon-Guibout V, Gayet N, NicolasChanoine M-H (2009) Early diagnosis of extra-pulmonary tuberculosis by a new procedure combining broth culture and PCR. J Clin Microbiol 47: 1452-1457.

5. Soini H and Musser JM (2001) Molecular diagnosis of mycobacteria. Clin Chem 47: 809-814.

6. Del Portillo P, Murillo LA, Patarroyo ME (1991) Amplification of a species specific DNA fragment of $M$. tuberculosis and its possible use in diagnosis. J Clin Microbiol 29: 2163-2168.

7. Negi SS, Anand R, Pasha ST, Gupta S, Basir SF, Khare S, Lal S (2007) Diagnostic potential of IS6110, 38KDa, and $85 \mathrm{~B}$ sequence based polymerase chain reaction in the diagnosis of $M$. tuberculosis in clinical samples. Indian $\mathbf{J}$ Med Microbiol 25: 43-49.

8. Ashok Rattan (2000) PCR for diagnosis of tuberculosis: where are we now? Indian J Tuberc 47: 79-82.

9. Kesarwani RC, Pandey A, Misra A, Singh A (2004) Polymerase chain reaction (PCR): Its comparison with conventional techniques for diagnosis of extra-pulmonary tubercular diseases. Indian J Surg 66: 84-88.

10. Clarridge JE, Shawar RM, Shinnick TM, Plikaytis BB (1993) Large-scale use of polymerase chain reaction for detection of $M$. tuberculosis in a routine mycobacteriology laboratory. J Clin Microbiol 31: 2049-2056.

11. Sekar B, Selvaraj L, Alexis A, Ravi S, Arunagiri K, Rathinavel L (2008) The utility of IS6110 sequence based polymerase chain reaction in comparison to conventional methods in the diagnosis of extra-pulmonary tuberculosis. Indian J Med Microbiol 26: 352-535.

12. Kerry H. Lok, Benjamin WH, Jr, Kimerling ME, Virgina Pruitt V, Lathan M, Razeq J, Nancy Hooper N, Cronin W, Dunlap NE (2002) Molecular differentiation of Mycobacterium tuberculosis strains without IS6110 insertions. Emerg Infect Dis 8: 1303-1305.

13. Das S, Paramasivan CN, Lewis DB, Prabhakar R, Narayanan PR (1995) IS6110 restriction fragment length polymorphism typing of clinical isolates of Mycobacterium tuberculosis from patients with pulmonary tuberculosis in Madras, south India. Tubercle Lung Dis 76: 550-554.

14. Sujatha N, Vijayalakshmi P, Narayannan PR, Venkatesan $P$, Girish C, Mahadevan S, Sarala Rajajee (2001) Evaluation of PCR using $\mathrm{TRC}_{4}$ and IS6110 primers in detection of tuberculous meningitis. J Clin Microbiol 39: 2006-2008.

15. Parandaman V, Narayanan S, Narayanan PR (Aug 2000) Utility of polymerase chain reaction using two probes for rapid diagnosis of tubercular pleuritis in comparison to conventional methods. Indian J Med Res 112: 47-51.

16. Watt B, Rayner A, Harris G (1996) Mycobacterium. In: ColleeJG, Fraser AG, Marmion BP, Simmons A, editors. Mackie and McCartney practical medical microbiology. 14th ed. London: Churchill Livingstone, p. 329-330.

17. Steingart KR, Henry M, Ng V, Hopewell PC, Ramsay A, Cunningham J, Urbanczik R, Perkins M, Aziz MA, Pai M (2006) Fluorescence versus conventional sputum microscopy for Tuberculosis: A systematic review. Lancet Infect Dis $6: 570-81$.

18. Cave MD, Eisenach KD, McDermott PF, Bates JH, Crawford JT 1991) IS6110: Conservation of sequence in the Mycobacterium tuberculosis complex and its use in DNA fingerprinting. Mol Cell Probes 5: 73-80.

19. Tiwari V, Jain.A, Verma RK (2003) Application of enzyme amplified mycobacterial DNA detection in the diagnosis of pulmonary and extra-pulmonary tuberculosis. Indian J Med Res 118: 224-228.

20. Agasino CB, Ponce de Leon A, Jasmer RM, Small PM (1998) Epidemiology of Mycobacterium tuberculosis strains in San Francisco that do not contain IS6110. Int J Tuberc Lung Dis 2: 518-520.

21. Totsch M, bocker W, Brommelkamp E, Fille M, Kreczy A, Ofner D, Schmid KW, Dockhorn-Dworniczak B (1996) Diagnostic value of different PCR assays for the detection of mycobacterial DNA in granulomatous lymphadenopathy. J Pathol 178: 221-226.

22. Peces R and Alvarez Jv (1987) Hypercalcemia and elevated $1,25(\mathrm{OH}) 2 \mathrm{D} 3$ levels in a dialysis patient with disseminated tuberculosis. Nephron 46: 377-379.

23. Peces R, de la Torre M, Alcazar F, Gago E (1998) Genitourinary tuberculosis as the cause of unexplained hypercalcaemia in a patient with pre-end-stage renal failure. Nephrol Dial Transplant 13: 488-490.

24. Das P, Ahuja A, Gupta SD (2008) Incidence, etiopathogenesis and pathological aspects of genitourinary tuberculosis in India. Indian J Urol 24: 356-361.

25. Forbes BA and Hicks KES (1993) Direct detection of Mycobacterium tuberculosis in respiratory specimens in a clinical laboratory by polymerase chain reaction. J Clin Microbiol 31: 1688-1694.

26. Pfyffer GE, Kissling P, John EM, Welsher HM, Salfinger M, Weber R (1996) Diagnostic performance of amplified Mycobacterium tuberculosis direct test with cerebrospinal fluid, other non-respiratory and respiratory specimens. J Clin Microbiol 34: 834-841.

27. Strategic and Technical Advisory group for TB (STAG-TB). Report of the $10^{\text {th }}$ meeting $27^{\text {th }}-29^{\text {th }}$ Sep 2010. WHO/HTM/TB/2010.18. 


\section{Corresponding author}

Dr. Padma Srikanth, MD

Professor, Department of Microbiology

Sri Ramachandra Medical College \& Research Institute

Sri Ramachandra UniversityPorur,

Chennai - 600116 Tamil Nadu, India

Telephone: 044-24768403 Extn. No 230; +91-9884389682

Email: srikanth_padma@rediffmail.com

Conflict of interests: No conflict of interests is declared. 